\title{
Research status and analysis of technology application for magnetic adsorption wall-climbing robots in China
}

\author{
H.J. Li \& J.J. Yan \& Y.W. Liu \& W. Chen \\ Wuhan Textile University, China, Wuhan
}

\begin{abstract}
Keywords: Magnetic adsorption; Wall-climbing robot; Research status; Analysis of technology application.
\end{abstract}

\begin{abstract}
Since the Japan's A.NISHI designs a wall-climbing robots prototype which based on the principle of negative pressure in 1966, wall-climbing robots technology has been rapid development in the world. No matter from the aspects of adsorption methods, movement forms or application ways have made considerable progress, in the nearly 50 years of development history, although the various of research results emerge in endlessly , the application prospect of wall-climbing robots research are not optimistic and have few application results , and most of research are in the basic research stage and fall into the technical bottleneck. This paper combines the research status of magnetic adsorption climbing robot in china, and analysis the difficulties of existing technology and discuss future development and application prospect of wall-climbing robots.
\end{abstract}

\section{Introduction}

The robot is a product which combined with the traditional mechanism and modern electronic technology (Liu, S. X. 1999), Wall-climbing robot, as an important part of the mobile robots field, combined the moving mechanism (wheel, crawler, legs etc.) with the adsorption mechanism which absorb it on the wall (magnet, sucker, according the use environment to select) to achieve, It makes the ground mobile technology to expand to the vertical space, enriching the scope of application of the mobile robot. As early as 1966, Japan's A.N ISHI (A.NISHI.1996) has devised a simple prototype robot, the principle is to use the electric fan air intake, producing low pressure air, and it is made by produce negative pressure as adsorption dynamics, which was seen as the beginning of the research on the wall-climbing robot. Since then, wall-climbing robot technology has been rapid development in the world. This paper combined with the latest achievements of typical climbing wall robot to summarize and analyze the research status of wall -climbing robot, and discussed the application in the future.

\section{Magnetic adsorption Wall-climbing robot research status in China}

Domestic robot research started relatively late, with the help of national "863" project funding, robot research institute of harbin institute of technology succeed to develop multi tracked tank wall spraying detected magnetic Wall-climbing robot Until 1996 (Wang, Y. 1996). As shown in figure 1, this robot is mainly for the oil storage and water storage steel cans, regular sand blasting, painting anti-corrosion paint, coating thickness detection in oil industry, which is not conducive to the work of the artificial operation to develop special equipment.

As the domestic development of wall-climbing robot research earlier units, it has been developed application of the detection field of wall-climbing robot (Wu, S. Q. 2006) such as shown in Figure 2 in the process of subsequent development, which based on negative pressure adsorption. At the same time, the domestic wall-climbing robot research has expanded gradually, more representative of the domestic university like Shanghai Jiao Tong University, Dalian Maritime University and Tsinghua University and Ningbo University etc.

Domestic climbing wall robot technology research which is relatively mature is the magnetic adsorption wall-climbing robot, most of it focuses on the application, mainly used for oil tank 
detection and hull wall cleaning, rust removing, weld inspection etc, and forms of motion mainly use tracked or wheeled.

Application of permanent magnetic adsorption climbing wall robot research object structure has three characteristics:

(1) They all need the regular inspection, repair and maintenance;

(2)Their surfaces are columnar or uneven wall;

(3)They are belongs to the steel wall, and easy to be magnet adsorbed.

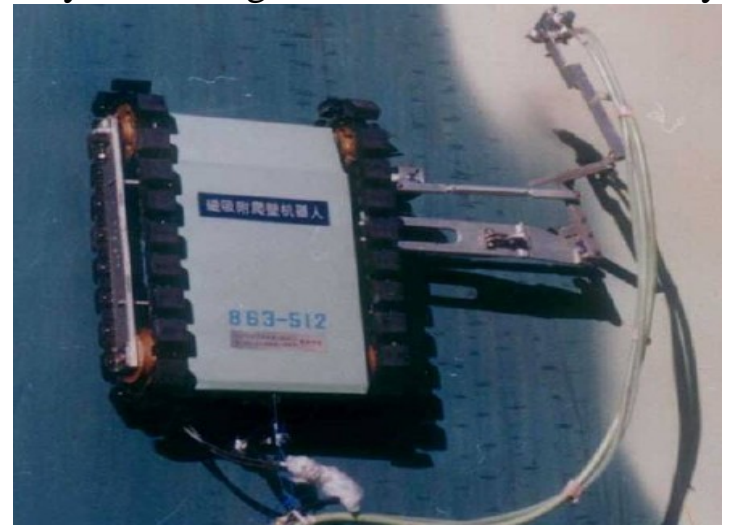

Fig1 Magnetic adsorption climbing robot

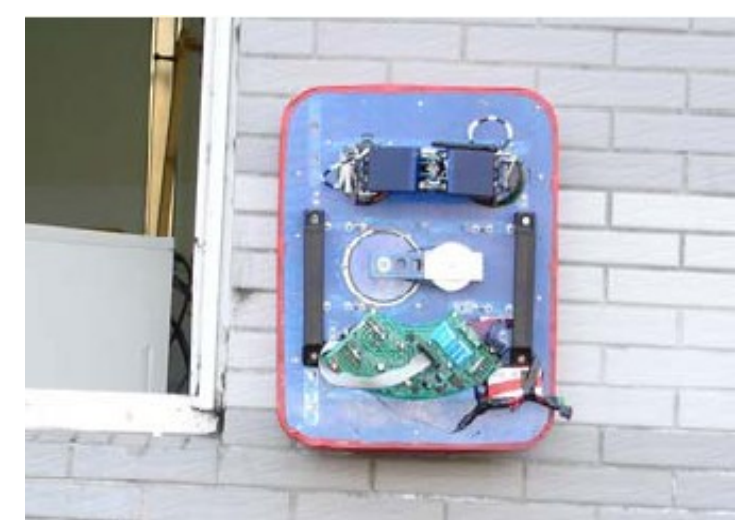

Fig2 Investigation of wall climbing robot

Shanghai Jiao Tong University’s Xu zeliang, Ma peisun (Xu, Z.L. 2004) describes as shown in Figure 3 based on rare earth uniform magnetization permanent magnet and it is different from the traditional ordinary sucker structure of caterpillar band body magnetization tracked wall-climbing robot.

Wen Jing (Wen, J. 2012) developed the robot based on the oil tank cleaning and inspection work of climbing, as shown in figure 4, it did not make the major changes in the mechanical structure, but mainly study for robot variable magnetic adsorption element, according to the finite element simulation to obtain the distribution of magnetic induction intensity and magnetic adsorption force, developing the control system based on. Visual C++, Upper and lower position machine control of robot at the same time.
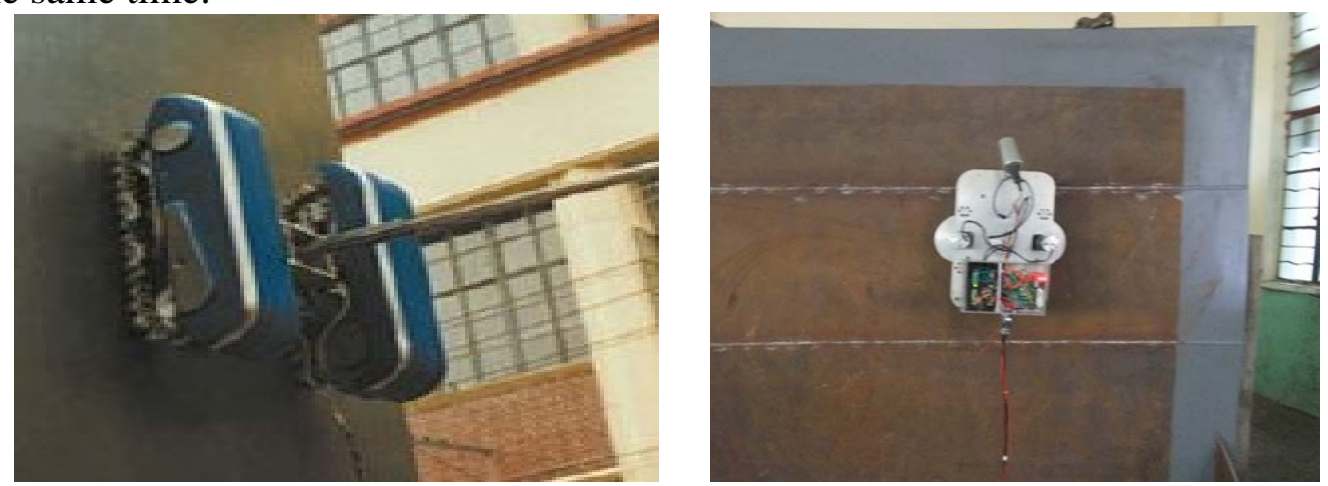

Fig.3 Multi-body magnetization climbing robot Fig.4 Variable magnetic-type climbing robot

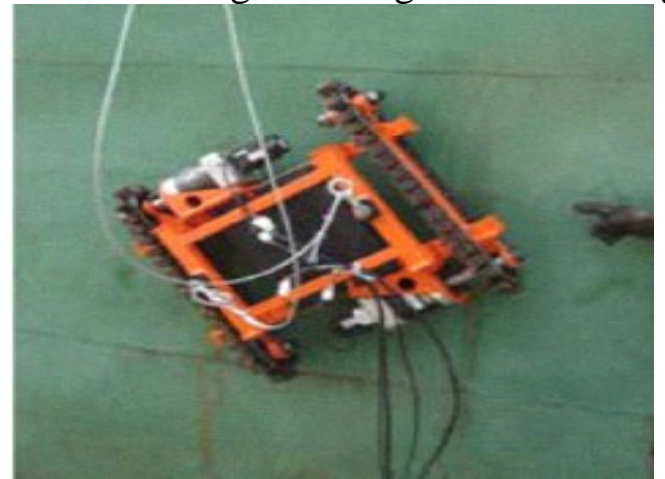

Fig.5 Magnetic and vacuum mixed type climbing robot 
Yi zhengyao (Yi, Z. Y. 2010), which come from Dalian Maritime University, developed a crawler type permanent magnetic vacuum mixed adsorption climbing robot, as shown in Figure 5, mainly used for ship wall rust removal. The robot features is huge, the load capacity is strong due to use the permanent magnetic adsorption, in addition the robot can climb the wall with height changes automatically to adjust the robot load mass and center of gravity.

Ningbo University's Chen Wei(2) designed and developed the hull polishing small robot warped surface walking system, using RecurDyn software for surface adaptive effects of walking system dynamics research, simulation of small robots in regular surfaces and warped surface motion, using workbench to establish static magnetic analysis for the individual adsorption unit, analyzed the influence of the thickness of the steel plate and the air gap on the adsorption capacity, so as to fill the lack of permanent magnetic adsorption type wall climbing robot in the adsorption theory, and obtain the good effect in the experiment of motion as shown in Figure 6.

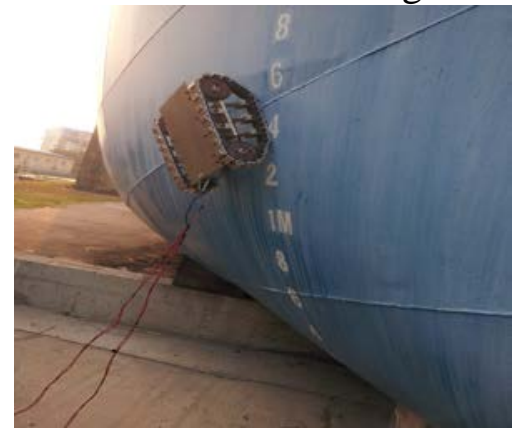

Fig.6 Ship warped surface polishing small walking robot walking system

\section{Wall climbing robot technology status and Analysis of APPLICATION}

\subsection{Wall climbing robot technology status}

At present, different research direction of wall-climbing robot is mainly attributed to two points: The adsorption mode and mode of motion. According to the research status, most of researchers select adsorption method based on the use, For example, working in the glass or on the smooth wall surface, mainly adopts vacuum adsorption or bionic adsorption, mainly

adopts magnetic adsorption in the steel wall , mainly includes the permanent magnetic adsorption and the electromagnetic absorption ; Mixed adsorption mode is used in mostly complex wall or curved wall, the current climbing robot adsorption mode mainly have the following kinds as shown in table 1:

If in the form of movement points, it can be divided into wheeled, crawler, foot type and frame type, their work application approach depends on the condition of the wall surface, and selecting after use the adsorption mode assembly, on the whole, it is fix on application way .

Table 1 Performance comparison of different adsorption manners climbing wall robot

\begin{tabular}{|c|c|c|c|c|c|}
\hline & $\begin{array}{c}\text { Adsorption } \\
\text { capacity }\end{array}$ & Load capacity & Its weight & $\begin{array}{c}\text { Adaptive } \\
\text { ability }\end{array}$ & $\begin{array}{c}\text { Technical } \\
\text { universality }\end{array}$ \\
\hline $\begin{array}{c}\text { Vacuum } \\
\text { adsorption }\end{array}$ & Better & general & general & general & Better \\
\hline $\begin{array}{l}\text { Magnetic } \\
\text { adsorption }\end{array}$ & strong & strong & heavy & strong & general \\
\hline $\begin{array}{l}\text { Biomimetic } \\
\text { adsorption }\end{array}$ & general & bad & More light & general & general \\
\hline $\begin{array}{c}\text { Electrostatic } \\
\text { adsorption }\end{array}$ & bad & bad & light & general & bad \\
\hline $\begin{array}{c}\text { Thrust } \\
\text { adsorption }\end{array}$ & strong & strong & heavy & general & general \\
\hline $\begin{array}{c}\text { Mechanical } \\
\text { adsorption }\end{array}$ & strong & strong & heavy & general & good \\
\hline
\end{tabular}




\subsection{Analysis of wall climbing robot application}

Combined with the analysis and comparison the technical status to see, wall-climbing robot research has made certain achievements after decades of research and development. But there is a big gap in the industrialization or research applications, at present most of research results are in the prototype verification stage .In general, wall-climbing robot technology also has some insurmountable problems:

(1)The gap between industrial application and prototype verification. At present, wall-climbing robot research is basically aimed at the application of a certain industry, therefore, the research content must have limitations, unable to break through some of the specific mode of thinking, thus restricting its on the path of industrialization, at the same time, the scope of the Industry application area has also been greatly restricted.

(2)The contradiction between the flexibility and stability of adsorption. The two themes of the wall-climbing robot are the movement form and adsorption methods. And the two are conflicting, the more flexible motion, its adsorption force should be

as small as possible. But considering with security, the adsorption force greater, the security better, it has formed a vicious circle: the adsorption capacity greater, the sports performance is poor; the sports performance is better, adsorption force would be insufficient. So you need to find a compromise point in the cycle, this compromise way could cause congenital defects in design and manufacture of prototype.

Research and function of bionic run in opposite directions. Now the wall-climbing robot research mostly trend of bionic direction research and development, like adsorption type as above mentioned, biped adsorption type are based on imitation of animal, human action and developed, this way is relatively difficult to control, and the function is relatively poor, the biggest problem is unable to provide the corresponding industrial application direction, that is to say the results of research is only limited to experimental verification, and the research value is greatly reduced.

\section{Acknowledgement}

The work was supported by the key foundation of Wuhan Textile University under grant No.133037.

\section{References}

[1] NISHI.1996.Development of wall-climbing robots. Computers Elect. Engng22 (2):123-149.

[2] Chen, W.2014.Ship warped surface polishing small robot walking system. Ningbo University

[3] Liu,S.X. 1999. The application of wall-climbing robot. Robot 21(2):148-155.

[4] Wang,Y. 1996. Painting of wall climbing robot with pedrail type magnet. Robot (Suppl.) 18:783-786.

[5] Wu, S. Q. 2006.A Wireless Distributed Wall Climbing Robotic System for Reconnaissance Purpose. Proceedings of the 2006 IEEE International Conference on Mechatronics and Automation: 1308-1312.

[6] Wen, J. 2012. The tank wall crawling robot body design and Study on its characteristics. Shanghai Jiaotong University.

[7] Xu,Z.L. 2004. Design and optimization of the caterpillar of wall climbing robot multi body magnetization structure suction. Chinese Journal of Mechanical Engineering40 (3):168-172.

[8] Yi,Z.Y. 2010. New vessel wall cleaning climbing robot dynamics modeling and analysis. Chinese Journal of Mechanical Engineering46 (15):23-30. 